Journal of Advanced Research in Fluid Mechanics and Thermal Sciences

\title{
Application and Treatment of Dye Congo Red, Metal and COD Retention by Modified Membranes Texture
}

\author{
Khaled Zaiter ${ }^{1,}$, Aissa Belouatek ${ }^{1}$, Boubekeur Asli ${ }^{1}$, Anthony Szymczyk ${ }^{2}$ \\ 1 Structure, Elaboration and Application of Molecular Materials Laboratory, Faculty of Exact Sciences and Informatics, Abdelhamid Ibn Badis, \\ University of Mostaganem, 27000, Algeria \\ 2 University of Rennes, National School of Chemistry of Rennes, CNRS, ISCR - UMR 6226, F-35000 Rennes, France
}

\section{ARTICLE INFO}

\section{Article history:}

Received 24 October 2019

Received in revised form 19 March 2020

Accepted 21 March 2020

Available online 30 June 2020

\section{Keywords:}

Clay; material oxides; dye; membrane; filtration; retention rate; effluent

\section{ABSTRACT}

In materials research, the development of ceramic products is extremely interesting in the field of the membrane supports because of their mechanical resistance, chemical inertia, long working life and thermal stability. Research is currently directed towards the exploitation of materials at a lower cost. The application of ceramic membrane was believed can be utilized not only for medical and oxygen separation but also for various industry such as food and beverages industry, textile industry, metal industry and environmental. The purpose of this work is the development of modified ceramic support based on kaolin for liquid waste processing. The study of the water flow and filtration through the supports made possible to highlight a variation of retention rate varying from 99 to $100 \%$ in function of composition, pore diameter, ion interaction and molecular weight. Tests of filtration of Congo red solutions, salts solution, lead solutions and industrial waste water were performed on modified support which was synthesized starting from a natural local barb tine. Mixed with aluminium oxide. Using Filtration of tangential type under an applied pressure of 5 bar.

Copyright @ 2020 PENERBIT AKADEMIA BARU - All rights reserved

\section{Introduction}

The wastewater treatment using membrane has rapidly increased during recent years and has emerged as an important separation and purification method in various process industries to prevent water resources pollution by toxic element such as Mercury $(\mathrm{Hg})$, cadmium (Cd) And dyes and are new used to obtain effluents without contamination [1].

A membrane is a physical barrier allowing selective transport of mass species. There are three large groups of membranes biological, organic (polymeric) and inorganic membranes. Inorganic membranes can be further classified into ceramic and metallic membranes [2]. The synthesis and characterization of ceramic membranes has been intensely studied due to their potential applications

\footnotetext{
* Corresponding author.

E-mail address: zaiterzaiterstst@gmail.com
}

https://doi.org/10.37934/arfmts.72.2.1324 
in the domains of gas separation [3-7], pervaporation [8,9], reverse osmosis [10] and nanofiltration [11-13], and the development of membrane reactors using catalytically active or passive inorganic. Membranes [14-21] disk and single-tube are the most common geometries of the microporous inorganic membranes.

The ceramic membrane can be used to sterilize the milk and whey, to purify the drinking water, to dewatering of products and the clarification of juice produced. For the textile industry, the ceramic membrane can use for desalination, separation of yeast and disposal of fat emulsions [22].

Silica sol deposition on alumina support layer membranes creates microporous silica which can be compared to reach very high helium permeation and selectivity [23].

Filtration separates constituents dissolved in the water from detritus and other solids that may alter the chemistry of the sample before it can be analyzed. However, filtration in the field adds the possibility of sample contamination if not done carefully [24].

The studies of inorganic membrane prepared entire by from clay and alumina, zircan silicate and the titan have just started $[25,26]$, the industry importance was attracted by this membrane sample which can be applied in liquid separation and gas. The sea products conservation industry is very important in Algeria, it generates a huge amount of wastewater, which is generally rejected in the littoral and is then responsible for an enormous pollution, by supporting the eutrophication phenomenon.

In this study, we investigate the development of ceramic membranes, based on Algeria natural materials which are in abundance and need lower firing temperature. The applications of this membrane prepared from kaolin mixed with a percentage of $\mathrm{Al}_{2} \mathrm{O}_{3}$ and coated with thin layer of alkoxide triethoxid-alumina in filtration process were used for the treatment and discoloration of effluent (dyes, heavy metals, salts and industrial waste) from wastewater [27-30]. This support membrane can be regenerated manually through gentle scraping or chemically using hydrochloride acid $(\mathrm{PH}=3)$ or sodium hydroxides solution $(\mathrm{PH}=10)[31]$.

\section{Materials and Methods}

\subsection{Support}

In the elaboration of the membrane support starting from Clay sample kaolin type of local origin [28] paste from Algeria material. The support prepared has the same configuration of tube monochannel, the equal length(L) $30 \mathrm{~cm}$ and equal diameter (D) $3 \mathrm{~cm}$ in the laboratory.

The different support was obtained by mixture of kaolin from Algeria and alumina $\mathrm{Al}_{2} \mathrm{O}_{3}$ with $15 \%$ percentage of weight and heated at $1100{ }^{\circ} \mathrm{C}$. after a casting, the supports were symbolized by SMS, [32-34] but the elaboration must be improved by adding an intermediate thin active layer with smaller pore sizes to the support SMS. The active layer was of alkoxide triethoxid-alumina, and prepared by sol - gel method in laboratories must be casting to $750^{\circ} \mathrm{C}$ and at this level temperature the layer which was deposited on a durable porous alumina. The results of the mixture were placed in a stainless steel. Then, the solution of $\mathrm{H}_{2} \mathrm{O}$ and acid solution $\mathrm{HNO}_{3}$ are added which was then heated at $750^{\circ} \mathrm{Cfor} 24$ hours [35].

For this study, the support SMS prepared from kaolinin the chemical composition presented in the Table 1 and $15 \%$ of weight of alumina $\mathrm{Al}_{2} \mathrm{O}_{3}$, and the $\mathrm{SMA}$ is a same of $\mathrm{SMS}$ but with a thin layer. the chemical analysis reveals that this support ceramic is essentially formed with a great amount of silicat and alumina, The cross section microstructures of sintered samples were observed using scanning electron microscopy(SEM) given images of the supports are reported as shown in Figure 1, which gives information on the texture of the surface of elaboration supports membrane ceramic SMA with an energy dispersive X-ray spectrometer phase analysis of the support SMS was identified 
by X-ray diffraction. The thermogravimetric analysis (ATG) differential scanning Calorimetry (DCS) the support SMA were performed with simultaneous DSC-TGA. the sample was heated from room temperature to $1000^{\circ} \mathrm{C}$ at a rate of $5^{\circ} \mathrm{C} / \mathrm{m}$ under static atmospheric conditions. The performance of cross flow filtration with different supports SMS and SMA were tested by tangential filtration performed on laboratory scale filtration pilot plant Figure 1 at a temperature set at $25^{\circ} \mathrm{C}$ and transmembrane pressure equate 5 bar and the flaw rate was set to $500 \mathrm{~L} / \mathrm{h}$.the membrane $\mathrm{SMS}$ and SMA was initially characterized by the determination of water permeability.

Table 1

The chemical composition of kaolin

\begin{tabular}{ll}
\hline Oxides & The mass percentage (\%) \\
\hline $\mathrm{SiO}_{2}$ & $49,5 \%$ \\
$\mathrm{Al}_{2} \mathrm{O}_{3}$ & $35,5 \%$ \\
$\mathrm{TiO}_{2}$ & $<0,3$ \\
$\mathrm{~K}_{2} \mathrm{O}$ & 1,55 \\
$\mathrm{Na}_{2} \mathrm{O}$ & $<0,1$ \\
$\mathrm{CaO}$ & $<0,1$ \\
$\mathrm{MgO}$ & $<0,4$ \\
$\mathrm{PF}$ & 11,8 \\
\hline
\end{tabular}

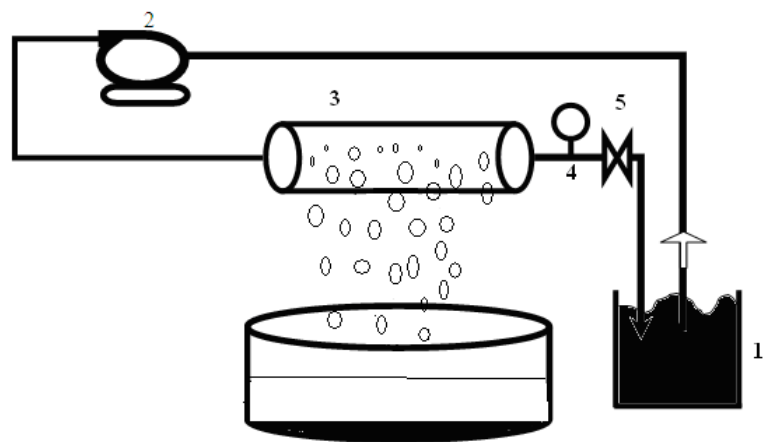

Fig. 1. Schematic diagram of the experimental apparatus filtration flow diagram [30]. 1. Feed tank;2. Feed pump; 3. Tubular membrane ceramic; 4. Pressure gage; 5 . Pressure valve; 6. Filtrate recovers

\subsection{Characterization of the Support}

Figure 2 and 3 presents the XRD patterns of raw thermally treated clay of supports SMS, it shows that all the peaks in difractogramme due to KAOLINITE (1), Muscovite (2) and Quartz (3) are the main minerals present in the raw clay. After casting at a temperature of $1100{ }^{\circ} \mathrm{C}$ peaks of (1and 2) disappear also, were as peaks of Mullit (4) appear due to the transformation of metakaolinite. The peaks of quartz (3) confirms the thermal stability of this phase that remain the peaks of Silica Morphed (5) and the alumina gives the polymorph structure presented with the peaks $\mathrm{Al}_{2} \mathrm{O}_{3} \gamma(6)$ and $\mathrm{Al}_{2} \mathrm{O}_{3} \beta$ (7). 


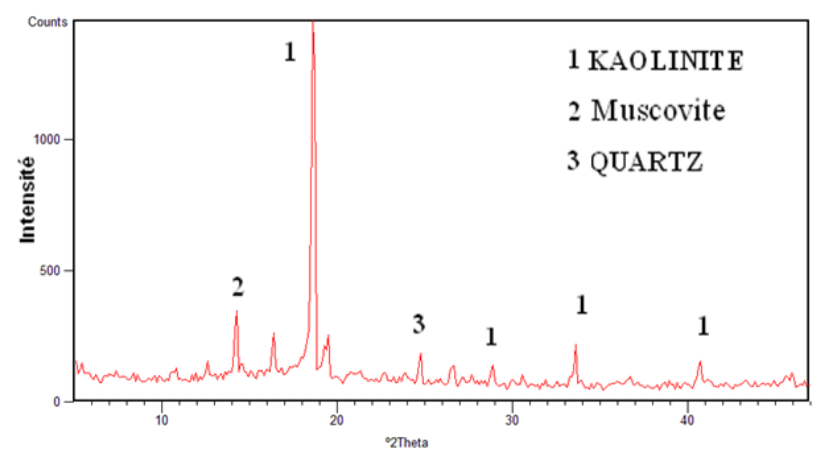

Fig. 2. X-ray diffractogram of the mixture of kaolin and $15 \% \mathrm{Al}_{2} \mathrm{O}_{3}$ raw powder

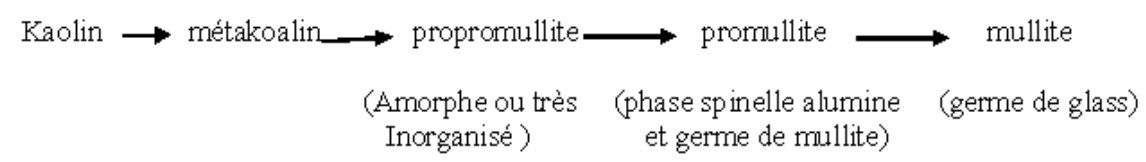

métakoalin $\longrightarrow$ mullite + silice libre (18)

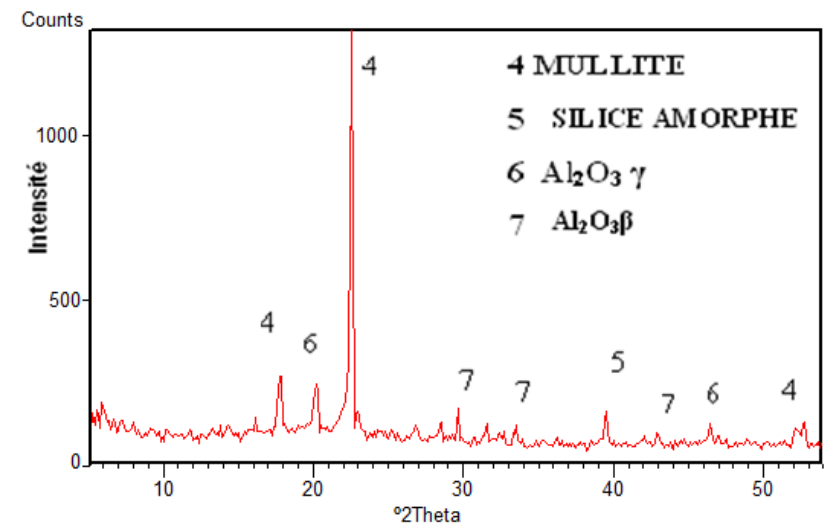

Fig. 3. X-ray difractogramme of the mixture of kaolin and $15 \% \mathrm{Al}_{2} \mathrm{O}_{3}$ heated to $1100^{\circ} \mathrm{C}$

\subsubsection{Thermal analysis}

At $65 \mathrm{C}^{\circ}$, there is an endothermic peak of Figure 4 Companied with mass loss, which were caused by the removal of residual physically adsorbed water in the simple. The second peak indicated organic components evaporated existing between $300^{\circ} \mathrm{C}$ and $400^{\circ} \mathrm{C}$. And finely around $520^{\circ} \mathrm{C}$ accompanied with $1.5 \%$ mass loss, which is due to the transition from kaolinite to meta-kaolinite and structural water. The exothermic at $850^{\circ} \mathrm{C}$ the peak corresponds to the formation of $\mathrm{Al}_{2} \mathrm{O}_{3}-\mathrm{Si}$ spinel $\mathrm{SiAl}_{2} \mathrm{O}_{4}$ by decomposition of meta-kaolinite. 


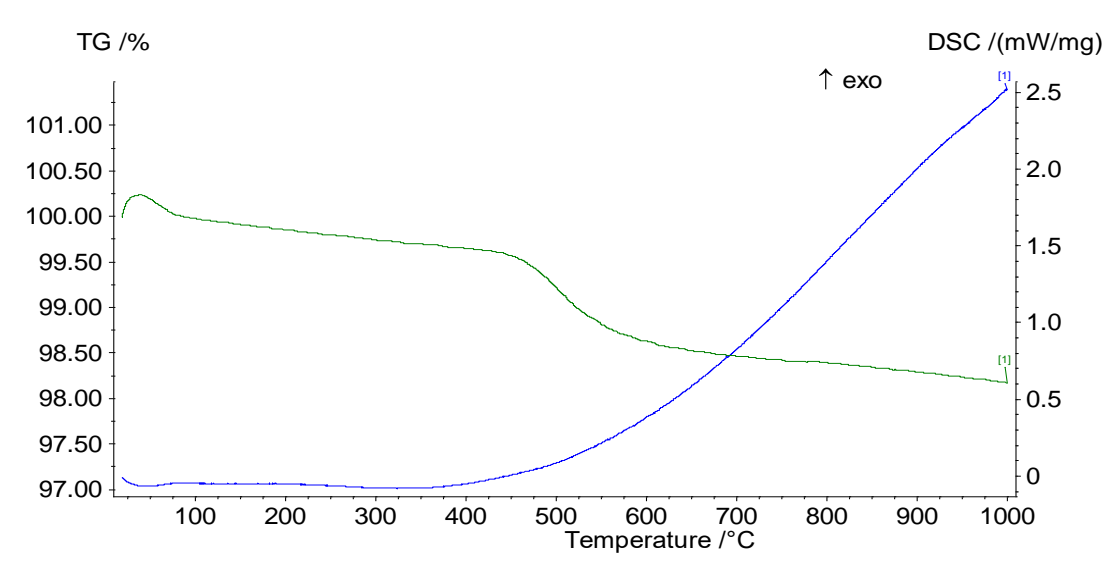

Fig. 4. Thermal analysis curve: DSC and TGA for SMC support

\subsubsection{Microstructure}

The morphology of the surface and cross-section were recorded at $10 \mathrm{Kv}$ voltage and amplification 3000 (Figure 5) .The image of Figure 5 also shows that the support surface was uniformly structure and was well covered by the alumina particles with a different heat done for the mullite and the transition transformation of amorphous glassy phase, And there was a range formed for all simple with the average pore size about 1.5- $2.5 \mu$ mand in hexagonal system. This porosity corresponded a transformation of the new crystalline phase for the first mullite to second mullite $[36,37]$.

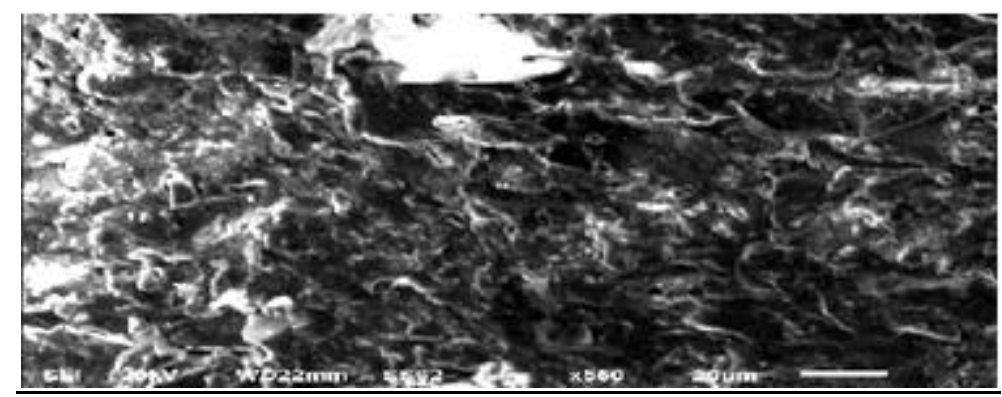

(a)

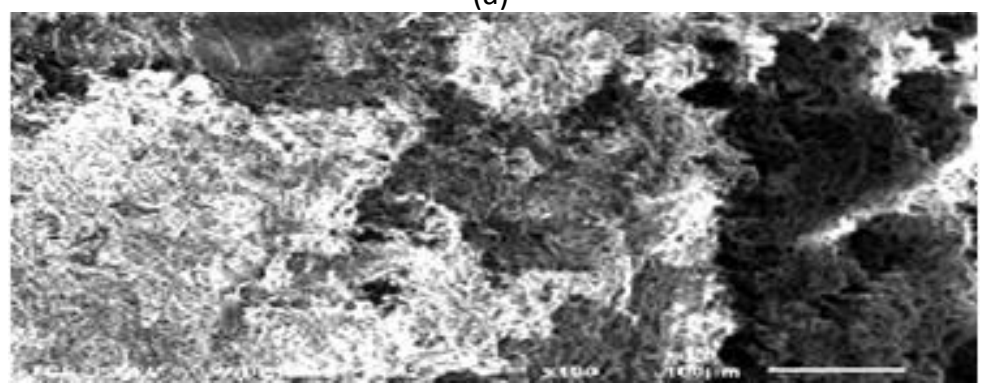

(b)

Fig. 5. SEM image of support SMS (kaolin and $15 \% \mathrm{Al}_{2} \mathrm{O}_{3}$ ) (a) surface section; (b) cross-section active

\section{Filtration Tests}

Figure 6,7 , and 8 , presents the variation of the retention rates of Congo red solution $\left(10^{-4} \mathrm{M}\right)$, lead solution $\left(10^{-4} \mathrm{M}\right)$ as a function of time Under a pressure of 5 bar for the supports SMS and SMA. 3.1 The Permeability as a Function of the Pressure of the Different Membranes 
Figure 6 shows that with increasing pressure values of the solution permeate flux increases linearly. A maximum permeate flux of supports SMS and SMA about $280 \mathrm{~L} / \mathrm{m}^{2} \mathrm{~h}, 1350 \mathrm{~L} / \mathrm{m}^{2} \mathrm{~h}$ was obtained at pressure values of 6 bar , at an initial permeate flux of SMS and SMA support respective represented $80 \mathrm{~L} / \mathrm{m}^{2} \mathrm{~h}$ and $210 \mathrm{~L} / \mathrm{m}^{2} \mathrm{~h}$ at 2 bar .the difference obtained is due to the variation of the morphology of the surface between SMS and SMA supports and the nature of layer geometry (smaller pore size ).

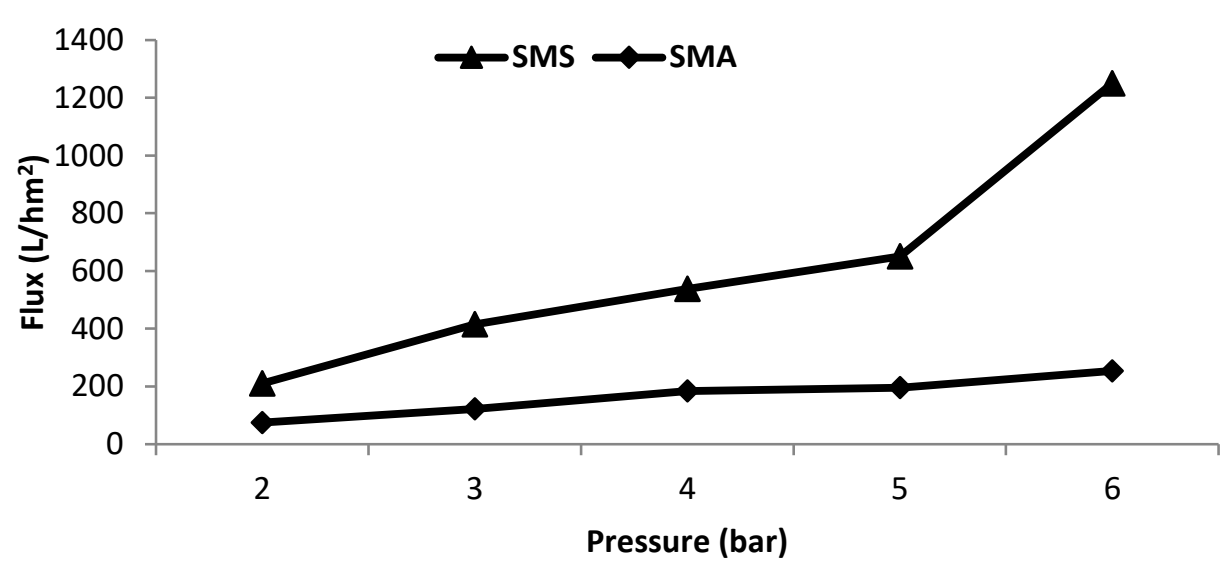

Fig. 6. Flux of water permeates versus the pressures of SMS and SMA

\subsection{Retention Rate}

The support SMS and SMA was checked to ensure that the permeability remains almost variable the filtration efficiency in removing of the dye and heavy metal from the feed solution was evaluated through the composition rejection which was calculated using the classical rejection coefficient

$R_{t} \%=1-\left[C_{P} / C_{0}\right] * 100$

where $C_{0}$ is the initial concentration of the dye in the feed solution and $C_{p}$ is the dye concentration in the permeate. In this test, it was found the permeate quality in terms of removal of dye (Congo Red) and heavy metal (lead $\mathrm{Pb}^{2+}$ ), $\mathrm{COD}$ (chemical organic demand) the reduction of this samples are shown in Figure 7, 8 and 9, respectively. The concentration is calculated by the law of beer lambert $A=C_{2} L$.

\subsubsection{Retention rate of dye solution (Congo red)}

Figures shows that the retention rate of Congo red solution as a function of time the results presented an important remark between SMS and SMA supports. That the good rejection is obtained with SMA support a $100 \%$ in 120 min, but support SMS the retention increases a function of time the Rt\% $=35 \%$ to $60 \%$ in $60 \mathrm{~min}$ and these values stand near $70 \%$ after $120 \mathrm{~min}$. The important parameter of this rejection consisted in the RC molecules are smaller than the SMA pore and the retention will be attributed to by the adsorption of dye and interaction between solute ions and material charge [38]. 


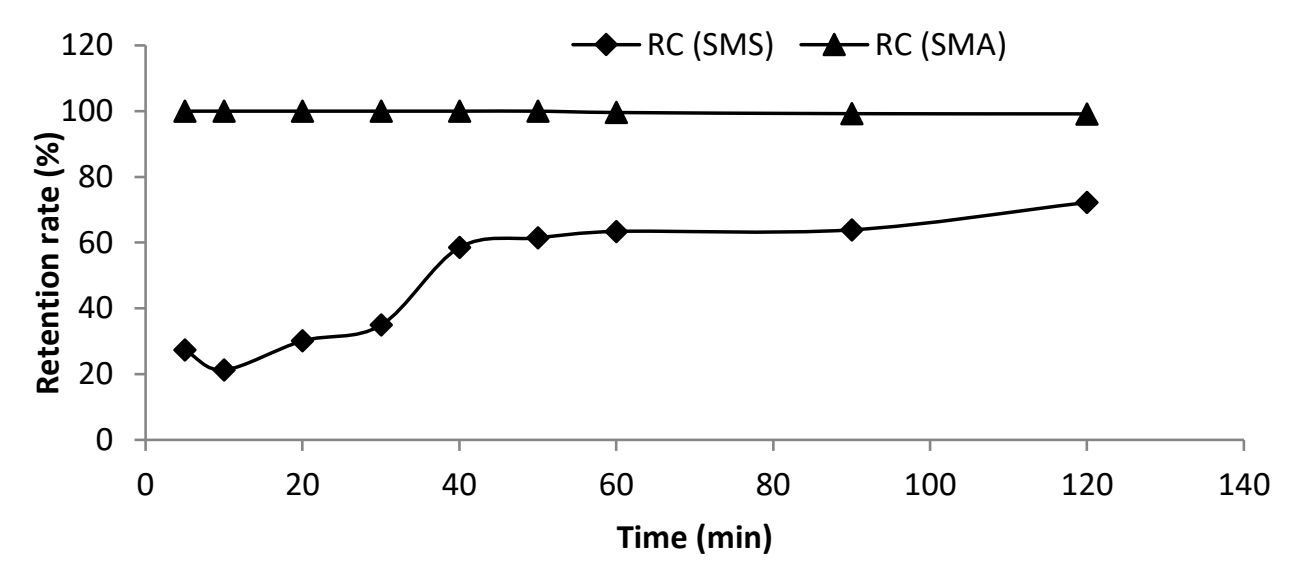

Fig. 7. Retention rate of Congo red solutions $\left(10^{-4} \mathrm{M}\right)$ versus time of the SMS and SMA supports ceramic membranes

\subsubsection{Retention rate of lead $\left(\mathrm{Pb}^{2+}\right)$}

The Figure below shows the variation of the retention rate according to the time(min) through the SMS and SMA supports as obtained from removal lead solution. The concentration of lead in the solution is $1000 \mathrm{ppm}$.

The coefficient where retention rate obtained with SMA support 100\% in 120 min of treatment filtration that the SMS support retention rate decries between a $75 \%$ to $20 \%$.

These results are in agreement with a previous study [39] that explained this phenomenon in terms of whey adsorption.

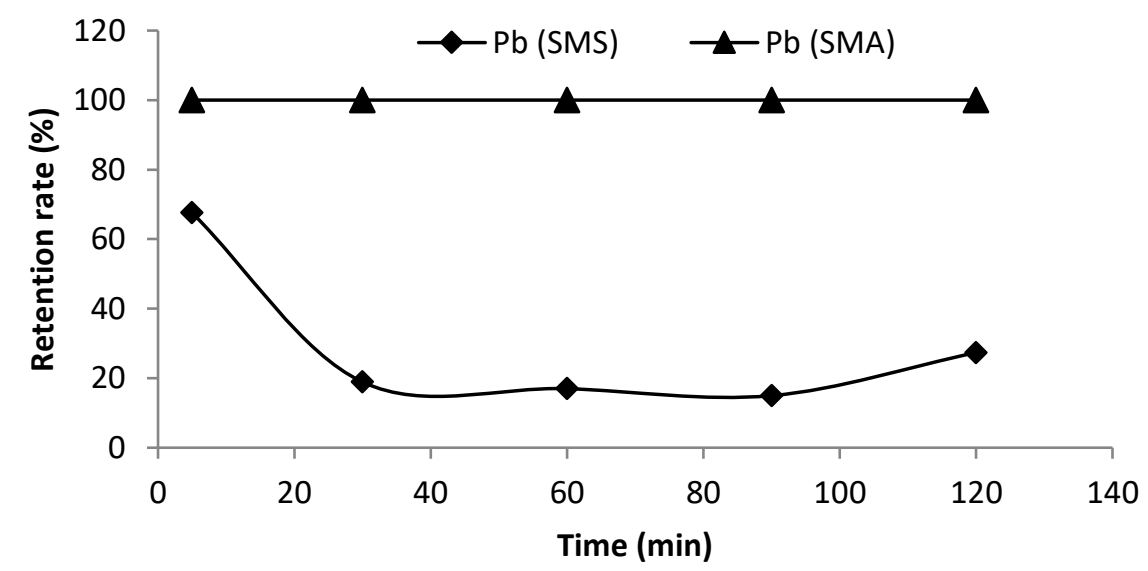

Fig. 8. Retention rate of lead solutionversus time of the SMS and SMA supports ceramic membranes

\subsubsection{COD reduction}

The supportt SMS can be used for the treatement of wastewater treatment produced by sea products conditioning in our case. The application of the test filtration a SMS in the effluent produced can give the good results. The used samples were collected from a reject product factory located in towns such us relizane, Timouchente and mostaganem (ALGERIA) effluents represented in the Table 2 with the characterization initial of the raw effluent. 
Table 2

the initial of the raw effluent characterization

\begin{tabular}{llll}
\hline Effluent & Conductivity $(\mu \mathrm{S} / \mathrm{cm})$ & $\mathrm{pH}$ & $\mathrm{COD}\left(\mathrm{mgO}_{2} / \mathrm{l}\right)$ \\
\hline BCR Factory & 1336 & 7,19 & 360 \\
Hydro Canal & 2481 & 9,87 & 280 \\
TUchlore & 4765 & 7,78 & 184 \\
UR.W.W & 1841 & 7,71 & 988 \\
\hline
\end{tabular}

The results of COD retention rate (COD is chemical organic demand determinated by calorimetric method) conform the efficiency of this filtration prepared SMS to effluent treatment. Figure 9 shows a noticeable elimination of suspension matter illustrated by the change of the samples of effluents colours as well as elimination of the turbidity the results of the COD with R.U efluent is very important there is reduction the $988 \mathrm{mg} \mathrm{d} \mathrm{O}_{2} / \mathrm{L}$ to175 $\mathrm{mg} \mathrm{d} \mathrm{d}_{2} / \mathrm{L}$ after $120 \mathrm{~min}$ of treatment. But for the effluent of BCR, SOACHLOR and Hydro- canal the notice of COD values obtained respective 360 $\mathrm{mg} \mathrm{d} \mathrm{d}_{2} / \mathrm{L}, 280 \mathrm{mg} \mathrm{d} \mathrm{d}_{2} / \mathrm{L}$ et $184 \mathrm{mg} \mathrm{d} \mathrm{O}_{2} / \mathrm{L}$ however the reduction is very low to a point commented of COD above $80 \mathrm{mg} \mathrm{d} \mathrm{d}_{2}$ / L. The VARIATION of COD evaluates according to the following order, where the reduction of COD is right in the environmental standard $120 \mathrm{mg} \mathrm{O}_{2} / \mathrm{L}$. Urban WASTEWATER > BCR factory> HYDRAUCANAL > TUchlore.

The results of the retention permeation salts in the versus time is represented with the Figure 10. The retention rate of the salted solutions $\left(\mathrm{MgSO}_{4}, \mathrm{MgCl}_{2}, \mathrm{Na}_{2} \mathrm{SO}_{4}\right.$ and $\left.\mathrm{NaCl}\right)$ at $10^{-4} \mathrm{M}$ of concentration through SMS and SMA supports variates between $8 \%$ and $50 \%$ in the $\mathrm{pH}$ of solution obtained 5,8 to 6,2 .

The SMA supports have a higher salt retention that the SMS support as clearly that the selectivity of retention rate for the SMA support increase with the sample salt solution containing $\mathrm{Na}_{2} \mathrm{SO}_{4}$ and $\mathrm{MgCl}_{2}$, that the retention rate obtained for $\mathrm{MgSO}_{4}$ solution is equal to 8\%after 120 min after filtration.

The beginning results of retention rate given by the SMS support follow the order: $\mathrm{Na}_{2} \mathrm{SO}_{4}>$ $\mathrm{MgSO}_{4}=\mathrm{NaCl}>\mathrm{MgCl}_{2}$. And with SMA support $\mathrm{Na}_{2} \mathrm{SO}_{4}>\mathrm{MgCl}_{2}>\mathrm{NaCl}>\mathrm{MgSO}_{4}$. We Can observe that the retention rate with bivalent ions is higher than monovalant ions.

The retention rate with SMS support is less and it strongly with SMA supports, it depends on the salt nature [40]. It has been postulated that the decrease in rejection rate of salt solution cult result from pore swelling and the increase due to repulsion forces between couterions ion in the electrical layer at the pore walls and / or from Hofmeister effects [41-44], That is a partial dehydratation of natural moleculars in the presence of ions because water would preferentially solvate ions. Therefore, the idea of sandwich was proposed in the study of $[45,46]$, to compensate for the imperfection of the pore size distribution of the available commercial membranes.

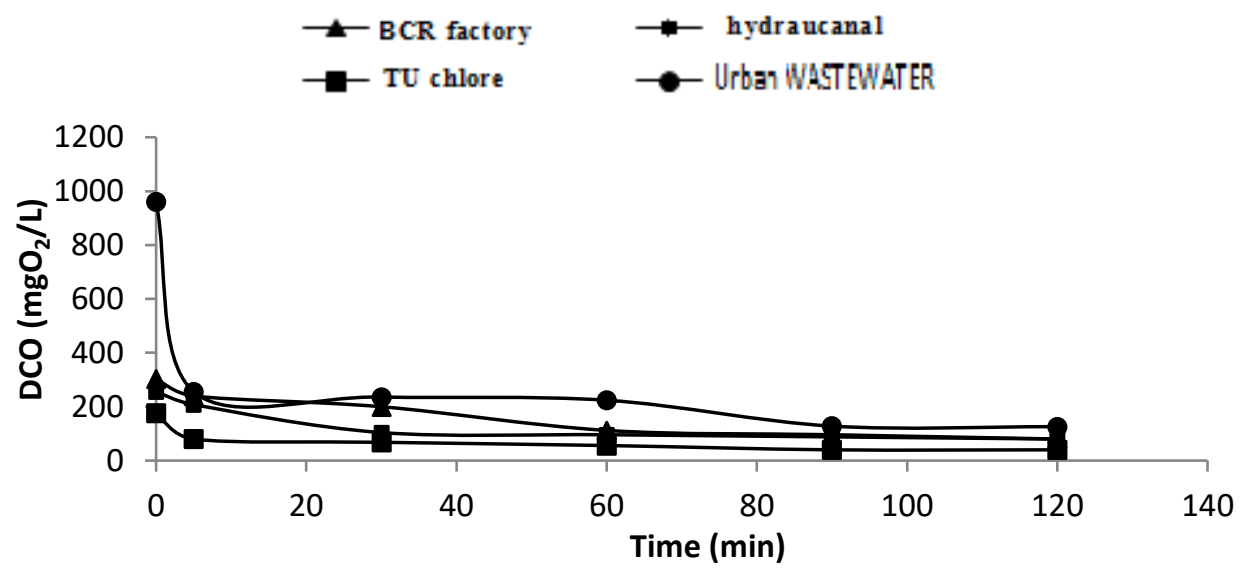

Fig. 9. Reduction of COD versus time of the SMS support ceramic membrane 


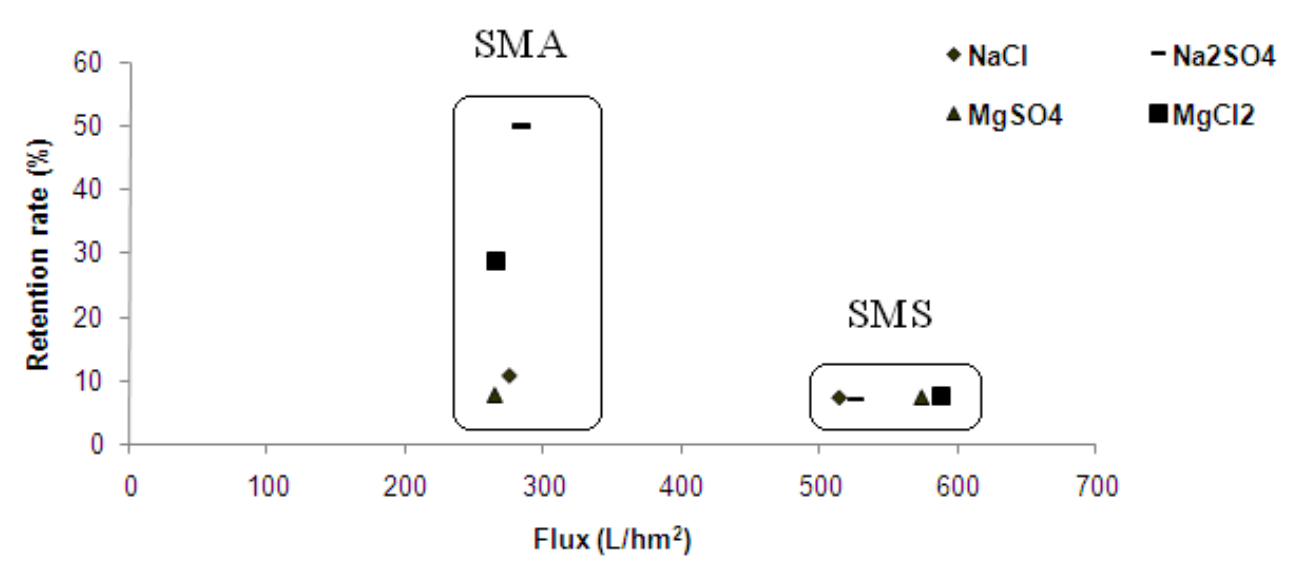

Fig. 10. The salt rejection of the permeated of membranes SMS and SMA

\section{Conclusions}

In this work, a novel low ceramic supports were prepared from local mineral kaolin and alumina oxide. It is confirmed that the sintering of support was fixed at $1100^{\circ} \mathrm{C}$, and the filtration layer deposited onto the support SMS was obtained by slip-casting method.

The support SMS and SMA shows that the permeat flux given is high about 1286,21 L/ hm² with SMS support and 270,3 L/ $\mathrm{hm}^{2}$ for SMA. The tast of filtration can be employed to separate the dye, salts and heavy metals from aqueous solution.

The result obtained for retention rate for congo red with SMS support between $75 \%$ to $20 \%$ and with SMA support rejection is $100 \%$ as well a same for the retention of lead (heavy metal). The SMA supports have a higher salt retention than SMS support as clearly that the selectivity has an important effect and depended to the charge repulsion that can coexist with adsorption phenomena. These supports have a retention rate COD a range $80 \%$, the increase in COD water filtrate may be explained with the desired pore sizes of filtration.

These membrane support SMS and SMA can also be used in wastewater produced by surface treatment in industry and have an interesting application in physical and biological decontamination.

\section{Acknowledgement}

My thanks to the Algerian Ministry of Higher Education and Scientific Research

\section{References}

[1] Chan, K. K., and A. M. Brownstein. "Ceramic membranes: growth prospects and opportunities." American Ceramic Society Bulletin 70, no. 4 (1991): 703-707.

[2] Baker, Richard W. Membrane technology and applications. John Wiley \& Sons, 2012. https://doi.org/10.1002/9781118359686

[3] Asaeda, M. "Microporous silica-based membranes-present status and prospect." In Proceedings of the 9th International Conference on Inorganic Membranes, ICIM9"'(R. Bredesen and H. Raeder, eds.), pp. 38-47. 2006.

[4] Asaeda, M., M. Ishida, and Y. Tasaka. "Pervaporation Characteristics of Silica-Zirconia Membranes for Separation of Aqueous Organic Solutions." Separation science and technology 40, no. 1-3 (2005): 239-254. https://doi.org/10.1081/SS-200041993

[5] Van den Broeke, L. J. P., F. Kapteijn, and J. A. Moulijn. "Transport and separation properties of a silicalite-1 membrane-II. Variable separation factor." Chemical engineering science 54, no. 2 (1999): 259-269. https://doi.org/10.1016/S0009-2509(98)00242-5

[6] Lin, Y. S. "Microporous and dense inorganic membranes: current status and prospective." Separation and Purification Technology 25, no. 1-3 (2001): 39-55. https://doi.org/10.1016/S1383-5866(01)00089-2 
[7] Lin, Y. S., I. Kumakiri, B. N. Nair, and H. Alsyouri. "Microporous inorganic membranes." Separation and Purification Methods 31, no. 2 (2002): 229-379.

https://doi.org/10.1081/SPM-120017009

[8] Bowen, Travis C., Richard D. Noble, and John L. Falconer. "Fundamentals and applications of pervaporation through zeolite membranes." Journal of Membrane Science 245, no. 1-2 (2004): 1-33.

https://doi.org/10.1016/i.memsci.2004.06.059

[9] Braunbarth, Carola M., Laura C. Boudreau, and Michael Tsapatsis. "Synthesis of ETS-4/TiO2 composite membranes and their pervaporation performance." Journal of Membrane science 174, no. 1 (2000): 31-42.

https://doi.org/10.1016/S0376-7388(00)00358-6

[10] Tsuru, Toshinori, Masashi Miyawaki, Tomohisa Yoshioka, and Masashi Asaeda. "Reverse osmosis of nonaqueous solutions through porous silica-zirconia membranes." AlChE journal 52, no. 2 (2006): 522-531.

https://doi.org/10.1002/aic.10654

[11] Van Gestel, Tim, Carlo Vandecasteele, Anita Buekenhoudt, Chris Dotremont, Jan Luyten, Bart Van der Bruggen, and Guido Maes. "Corrosion properties of alumina and titania NF membranes." Journal of Membrane Science 214, no. 1 (2003): 21-29.

https://doi.org/10.1016/S0376-7388(02)00517-3

[12] Guizard, Christian, André Ayral, and Anne Julbe. "Potentiality of organic solvents filtration with ceramic membranes. A comparison with polymer membranes." Desalination 147, no. 1-3 (2002): 275-280.

https://doi.org/10.1016/S0011-9164(02)00552-0

[13] Tsai, Chung-Yi, Siu-Yue Tam, Yunfeng Lu, and C. Jeffrey Brinker. "Dual-layer asymmetric microporous silica membranes." Journal of membrane science 169, no. 2 (2000): 255-268.

https://doi.org/10.1016/S0376-7388(99)00343-9

[14] Brunetti, A., G. Barbieri, E. Drioli, K-H. Lee, B. Sea, and D-W. Lee. "WGS reaction in a membrane reactor using a porous stainless steel supported silica membrane." Chemical Engineering and Processing: Process Intensification 46, no. 2 (2007): 119-126.

https://doi.org/10.1016/i.cep.2006.05.005

[15] Coronas, Joaquín, Richard D. Noble, and John L. Falconer. "Separations of C4 and C6 isomers in ZSM-5 tubular membranes." Industrial \& engineering chemistry research 37, no. 1 (1998): 166-176.

https://doi.org/10.1021/ie970462u

[16] Coronas, Joaquín, and Jesús Santamaría. "Separations using zeolite membranes." Separation and Purification methods 28, no. 2 (1999): 127-177.

https://doi.org/10.1080/03602549909351646

[17] Jafar, Jalal J., Peter M. Budd, and Ron Hughes. "Enhancement of esterification reaction yield using zeolite A vapour permeation membrane." Journal of Membrane Science 199, no. 1-2 (2002): 117-123. https://doi.org/10.1016/S0376-7388(01)00683-4

[18] Tanaka, Kazuhiro, Ryuuhei Yoshikawa, Cui Ying, Hidetoshi Kita, and Ken-ichi Okamoto. "Application of zeolite membranes to esterification reactions." Catalysis Today 67, no. 1-3 (2001): 121-125.

https://doi.org/10.1016/S0920-5861(01)00271-1

[19] Bowen, Travis C., Shiguang Li, Richard D. Noble, and John L. Falconer. "Driving force for pervaporation through zeolite membranes." Journal of membrane science 225, no. 1-2 (2003): 165-176.

https://doi.org/10.1016/i.memsci.2003.07.016

[20] Tsuru, Toshinori, Hiroaki Shintani, Tomohisa Yoshioka, and Masashi Asaeda. "A bimodal catalytic membrane having a hydrogen-permselective silica layer on a bimodal catalytic support: Preparation and application to the steam reforming of methane." Applied Catalysis A: General 302, no. 1 (2006): 78-85.

https://doi.org/10.1016/i.apcata.2005.12.029

[21] Tsuru, Toshinori, Takehiro Kan-no, Tomohisa Yoshioka, and Masashi Asaeda. "A photocatalytic membrane reactor for VOC decomposition using Pt-modified titanium oxide porous membranes." Journal of Membrane Science 280, no. 1-2 (2006): 156-162. https://doi.org/10.1016/i.memsci.2006.01.008

[22] Mohamed, Mohamad Atif, Norazlianie Sazali, Fatin Nurwahdah, and Nor Hasrul Akhmal. "A Short Review on Membranes for Helium Separation and Purifications."Journal of Advanced Research in Fluid Mechanics and Thermal Sciences 62, no. 1 (2019): 80-87.

[23] Fatin Nurwahdah Ahmad, Norazlianie Sazali, Safwan Shalbi, Nor Hasrul Akhmal Ngadiman, Mohd Hafiz Dzarfan Othman. "Oxygen Separation Process using Ceramic-Based Membrane." Journal of Advanced Research in Fluid Mechanics and Thermal Sciences 62, no. 1 (2019): 1-9.

[24] Nur Aleya Lokman, Ahmad Muhsin Ithnin, Muhammad Nashren Ramli, Nadia Dayana Bahar, Wira Jazair Yahya. "Effect of Filtered Palm Oil Mill Effluent (POME) via Close Loop In-Line Microbubbles Treatment Chamber for 
Biochemical Oxygen Demand (BOD) Treatment." Journal of Advanced Research in Fluid Mechanics and Thermal Sciences 61, n0. 1 (2019): 10-19.

[25] Brunetti, A., G. Barbieri, E. Drioli, K-H. Lee, B. Sea, and D-W. Lee. "WGS reaction in a membrane reactor using a porous stainless steel supported silica membrane." Chemical Engineering and Processing: Process Intensification 46, no. 2 (2007): 119-126.

https://doi.org/10.1016/i.cep.2006.05.005

[26] Wynn, Nick. "Dehydration with silica pervaporation membranes." Membrane Technology 2001, no. 129 (2001): 1011.

https://doi.org/10.1016/S0958-2118(01)80104-X

[27] Farmer, Victor Colin. Infrared spectra of minerals. Mineralogical society, 1974.

https://doi.org/10.1180/mono-4

[28] J. Temuujin, K. Okada, T. S. Jadambaa, K. J. D. MacKenzie, J. Amarsanaa. " Effect of grinding on the leaching behaviour of pyrophyllite." Journal of the European Ceramic Society 23, no. 8 (2003): 1277-1282. https://doi.org/10.1016/S0955-2219(02)00297-2

[29] Abdelmouleh, A. "Etude expérimentale de la valorisation de l'allache et de la seiche en Tunisie." PhD diss., Thése de doctorat, 1997.

[30] Adamczak, Hanna, Katarzyna Materna, Radosław Urbański, and Jan Szymanowski. "Ultrafiltration of micellar solutions containing phenols." Journal of colloid and interface science 218, no. 2 (1999): 359-368. https://doi.org/10.1006/icis.1999.6430

[31] Shanefield, Daniel J. Organic additives and ceramic processing: with applications in powder metallurgy, ink, and paint. Springer Science \& Business Media, 2013.

[32] Belouatek, Aissa, Nouredine Benderdouche, Ahmed Addou, Abdellah Ouagued, and Nourredine Bettahar. "Preparation of inorganic supports for liquid waste treatment." Microporous and mesoporous materials 85, no. 12 (2005): 163-168. https://doi.org/10.1016/j.micromeso.2005.06.007

[33] Belouatek, A. "Elaboration des supports microporeux et mise en oeuvre." These de Magister, Universite de Mostaganem, Algeria (1998).

[34] Belouatek, Aissa, Abdellah Ouagued, Mustapha Belhakem, and Ahmed Addou. "Filtration performance of microporous ceramic supports." Journal of biochemical and biophysical methods 70, no. 6 (2008): 1174-1179. https://doi.org/10.1016/j.jbbm.2007.08.004

[35] Yulia, Fayza, Agustino Zulys, and Rizky Ruliandini. "Metal-organic framework based chromium terephthalate (MIL$101 \mathrm{Cr}$ ) growth for carbon dioxide capture: A review." Journal of Advanced Research in Fluid Mechanics and Thermal Sciences 57, no. 2 (2019): 158-174.

[36] Belouatek, Aissa, Abdellah Ouagued, Mustapha Belhakem, and Ahmed Addou. "Filtration performance of microporous ceramic supports." Journal of biochemical and biophysical methods 70, no. 6 (2008): 1174-1179. https://doi.org/10.1016/j.jbbm.2007.08.004

[37] Belouatek, Aissa, Nouredine Benderdouche, Ahmed Addou, Abdellah Ouagued, and Nourredine Bettahar. "Preparation of inorganic supports for liquid waste treatment." Microporous and mesoporous materials 85, no. 1 2 (2005): 163-168. https://doi.org/10.1016/i.micromeso.2005.06.007

[38] RICQ, Laurence, Anthony SZYMCZYK, and Patrick FIEVET. "Electrokinetic methods employed in the characterization of microfiltration and ultrafiltration membranes." Surfactant science series 106 (2002): 583-617.

[39] Carić, Marijana Đ., Spasenija D. Milanović, Darko M. Krstić, and Miodrag N. Tekić. "Fouling of inorganic membranes by adsorption of whey proteins." Journal of membrane science 165, no. 1 (2000): 83-88.

https://doi.org/10.1016/S0376-7388(99)00221-5

[40] Manno, P., Philippe Moulin, J. C. Rouch, M. Clifton, and P. Aptel. "Mass transfer improvement in helically wound hollow fibre ultrafiltration modules: yeast suspensions." Separation and purification Technology 14, no. 1-3 (1998): 175-182. https://doi.org/10.1016/S1383-5866(98)00072-0

[41] Schaep, Johan, Bart Van der Bruggen, Carlo Vandecasteele, and Dirk Wilms. "Influence of ion size and charge in nanofiltration." Separation and Purification Technology 14, no. 1-3 (1998): 155-162. https://doi.org/10.1016/S1383-5866(98)00070-7

[42] Van der Bruggen, Bart, Johan Schaep, Dirk Wilms, and Carlo Vandecasteele. "Influence of molecular size, polarity and charge on the retention of organic molecules by nanofiltration." Journal of Membrane Science 156, no. 1 (1999): 29-41. https://doi.org/10.1016/S0376-7388(98)00326-3 
[43] Peeters, J. M. M., J. P. Boom, M. H. V. Mulder, and H. Strathmann. "Retention measurements of nanofiltration membranes with electrolyte solutions." Journal of membrane science 145, no. 2 (1998): 199-209.

https://doi.org/10.1016/S0376-7388(98)00079-9

[44] Schaep, Johan, Bart Van der Bruggen, Carlo Vandecasteele, and Dirk Wilms. "Influence of ion size and charge in nanofiltration." Separation and Purification Technology 14, no. 1-3 (1998): 155-162. https://doi.org/10.1016/S1383-5866(98)00070-7

[45] Mazlan, Nurul Ain, Khairul Faezah Md Yunos, Mohd Nazli Mohd Naim, and Azhari Samsu Baharuddin. "Performances of Sandwich Membrane in Reclamation of Water from Final Discharged POME." Journal of Advanced Research in Materials Science 47, no. 1 (2018): 1-8

[46] Mohammed Rafiq Abdul Kadir, and Ardiyansyah Syahrom. "Comparison of permeability on the actual and ideal cancellous bone microstructure." CFD Letters 1, no. 2 (2009): 68-77. 